\title{
A New Statistical Parameter for Determining Joint Roughness Coefficient (JRC) considering the Shear Direction and Contribution of Different Protrusions
}

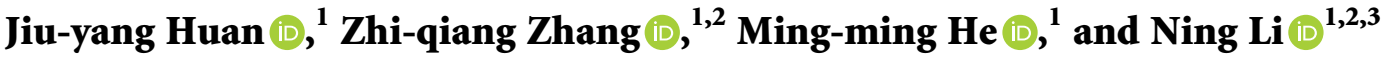 \\ ${ }^{1}$ Institute of Geotechnical Engineering, Xi'an University of Technology, Xi'an 710048, China \\ ${ }^{2}$ State Key Laboratory of Eco-hydraulics in Northwest Arid Region, Xi'an University of Technology, Xi'an 710048, China \\ ${ }^{3}$ Shaanxi Key Laboratory of Loess Mechanics and Engineering, Xi'an University of Technology, Xi'an 710048, China
}

Correspondence should be addressed to Zhi-qiang Zhang; zhangzq87@xaut.edu.cn

Received 7 November 2020; Revised 26 December 2020; Accepted 25 January 2021; Published 10 February 2021

Academic Editor: Zhi Cheng Tang

Copyright $\odot 2021$ Jiu-yang Huan et al. This is an open access article distributed under the Creative Commons Attribution License, which permits unrestricted use, distribution, and reproduction in any medium, provided the original work is properly cited.

The mechanical properties of joints are important factors affecting the safety and stability of rock mass. The joint roughness coefficient (JRC) is a parameter for describing the roughness morphology of the joint surface, and its accurate quantification is very important to predict the shear strength. In the current statistical parameter methods for the estimation of joint roughness, the size of different protrusions on the joint surface was completely ignored, which did not correspond to the real failure mechanism of rock joint during the shear process. In this study, a new statistical parameter WPA was proposed for the estimation of JRC considering the shear direction and the contributions of different protrusions. First, the 10 standard roughness joint profiles were digitized based on image processing technology, and the obtained coordinate data were proved to be reliable by the calculation results of existing parameters. Secondly, the WPA value of 10 standard roughness joint profiles was calculated at a $0.5 \mathrm{~mm}$ sampling interval in two directions. The functional relationship between WPA and JRC indicated that they should be established in the same shear direction to maintain a high correlation. The JRC values of 10 standard roughness joint profiles in direction 2 were obtained based on the functional relationship established between WPA and JRC in direction 1, and the roughness of these 10 joint profiles was confirmed to be influenced by direction. Next, the effect of sampling interval on WPA was investigated. As the sampling interval increases, the WPA values gradually decreased and the correlation between them and JRC gradually declined. In practical application, a smaller sampling interval was recommended for more accurate prediction. Finally, the geometric coordinate data of 21 joint profiles given in the literature and 4 natural joint surfaces were obtained by graphics processing technology and 3D scanning technology, respectively. The JRC values of them were separately estimated by WPA in different directions. The results showed that the new statistical parameter WPA proposed in this paper can well describe the joint roughness considering the shear direction and the contribution of different protrusions.

\section{Introduction}

In natural rock masses, there are complex joints and structural planes with different morphologies, directions, and scales. The engineering geology of the rock mass is obviously different from the complete rock due to the characteristics of multiple fractures. A lot of practical engineering experience showed that the fracture in the rock mass plays a leading role in the deformation and destruction of slope and tunnel engineering [1-4]. Therefore, the safety and stability of rock mass largely depended on the mechanical properties of intricate joints. Shear strength is the main strength characteristic of joints, and it is influenced by a variety of factors. Joint roughness is an important factor affecting the shear properties of the joint surface, and its quantitative determination makes it possible to predict the shear strength of the joint surface. Therefore, it is a challenging research task to accurately and reasonably estimate the roughness of the joint surface [5-9]. 
Based on the direct shear test of 136 natural joint specimens, Barton [8] proposed the JRC-JCS model which was widely used in rock mass engineering and put forward the joint roughness coefficient (JRC) to quantitatively describe the irregular morphology of the joint surface at the first time. The JRC-JCS model is shown in

$$
\tau=\sigma_{n} \tan \left[\mathrm{JRC} *\left(\frac{\mathrm{JCS}}{\sigma_{n}}\right)+\varphi_{r}\right],
$$

where $\tau$ is the shear strength, which can be obtained from the shear stress curve, $\sigma_{n}$ is the normal stress, JRC is the joint roughness coefficient, JCS is the compressive strength of the joint wall, which can be obtained from the uniaxial compression test or the point load test of the complete rock, and $\varphi_{b}$ is basic friction angle which can be obtained from the tilt test of the joint surface. For equation (1), if we have obtained the exact values of other parameters, we can get the JRC value by inverse calculation. However, this method can only provide a posteriori description of the roughness of the joint surface. In contrast, we prefer that the JRC and shear strength of the joint surface be obtained in advance to evaluate its safety and stability. According to this idea, Barton and Choubey [9] proposed 10 standard roughness joint profiles, and the JRC of the target joint can be determined by visual comparison. The JRC values of the standard profile were obtained by back calculation from equation (1) with a range of 0 to 20 , as shown in Table 1.

As this empirical comparison method gives the way to determine the JRC value for the first time, the International Society for Rock Mechanics [10] recommends these 10 profiles as a standard method for evaluating the joint roughness coefficient. Although the empirical comparison method was very convenient and fast, its prediction value fluctuated with the personal experience of field engineers $[11,12]$.

To avoid the above situation, the statistical parameter method was gradually developed to quantify the JRC of the joint surface, such as the straight edge method [13], the modified straight edge method [14], the fractal dimension (D) $[15,16]$, root mean square roughness index (RMS) and mean square values roughness index (MSV) [17], root mean square of the first deviation of profiles $\left(Z_{2}\right)$ [17-22], structure function $(S F)$ [17-19, 21-23], standard deviation of the angle $(S D i)$ [19], the roughness profile index $(R p)$ [19-23], maximum inclination $\left(\theta_{\max }^{*}\right)[20,21]$, the modified $Z_{2}\left(Z_{2}^{\prime}\right)[24]$, mean positive angle parameter $\left(\theta_{P+}\right)$ [25], and mean tangent angle $\left(\beta_{100 \%}\right)$ [22]. These parameters can be calculated from geometric coordinates of joint profile, as shown in Figure 1 [26], where $x_{i}$ and $y_{i}$ are the abscissa and ordinate of the joint profile, respectively. $L$ is the horizontal length of the joint profile. $\triangle x$ is the distance between the abscissa of adjacent coordinate point and it is usually a constant value at the same sampling interval.

It is practical to use JRC to systematically characterize the morphology of rock joints, and JRC provides a unified standard for all joint morphology description methods. However, the accuracy of JRC is highly dependent on the reasonableness of the statistical parameters used. At present, many researchers believed that the rough morphology of joint surface has anisotropy because the strength and failure characteristics of rough joints were completely different in different shear directions [27-30]. Therefore, the directionality of rough topography should be considered when describing joint roughness. Most of the above statistical parameters had been confirmed to have a good correlation with JRC [13-25]. However, only a few statistical parameters could reflect the influence of shear direction on joint roughness, such as $\theta_{\max }^{*}, Z_{2}^{\prime}, \theta_{P+}$, and $\beta_{100 \%}[20-22,24,25]$.

In recent years, some scholars had found that the failure of different morphologies of joint surfaces was different in the shear process $[7,31-35]$. The failure scale of the big protrusion on the joint surface was larger than that of the small one. This indicated that the overall failure of the joint surface was closely related to the size of the joint protrusion, and the overall roughness of the joint should consider the size of protrusion corresponding to local roughness. However, in the current statistical parameter methods for the estimation of joint roughness, only the geometric characteristics of the joint surface were considered. The overall roughness parameters of the joint profile were usually obtained by averaging all local roughness parameters. The size of joint protrusion was completely ignored, and this could not reflect the real failure mechanism of the joint in the shear process.

In order to predict the JRC of joint profile more reasonably, a new statistical parameter considered the contribution degree of different protrusions and shear direction was proposed in this paper. Based on the 10 standard roughness joint profiles proposed by Barton and Choubey [9], the directionality of JRC was well verified. What is more, the impact of the sampling interval of joint profile data on both the WPA value and their correlation with JRC was also investigated. Finally, the practicability of WPA in evaluating JRC of the joint profile was well verified based on the joint profile given in the literature and the natural joint surface.

\section{Derivation of New Statistical Parameters}

In order to fill the gaps in existing studies, a new statistical parameter WPA (the weighted positive angle) was proposed in this paper to characterize the roughness of the joint profile. In the definition of WPA, the directionality of the shear process and the contribution of local roughness to the overall roughness were considered simultaneously.

As shown in Figure 2, the discrete form of the rough joint profile consists of a series of coordinate points $\left(x_{i}, y_{i}\right)$, and the horizontal coordinate spacing between adjacent coordinate points is the sampling interval $\Delta x$. The horizontal line corresponding to the lowest point of the joint profile (the ordinate is $y_{\min }$ ) was defined as the lowest horizontal line, and the distance from the joint coordinate point to the lowest horizontal line was defined as the undulating height $h$. At the same sampling interval, the joint profile was divided into a few small joint segments, each of which could be considered as a microprotrusion. Finally, for a single microjoint segment, the area $(A)$ of the region enclosed by the joint profile and the lowest horizontal line was defined to 
TABLE 1: 10 standard roughness joint profiles [9].

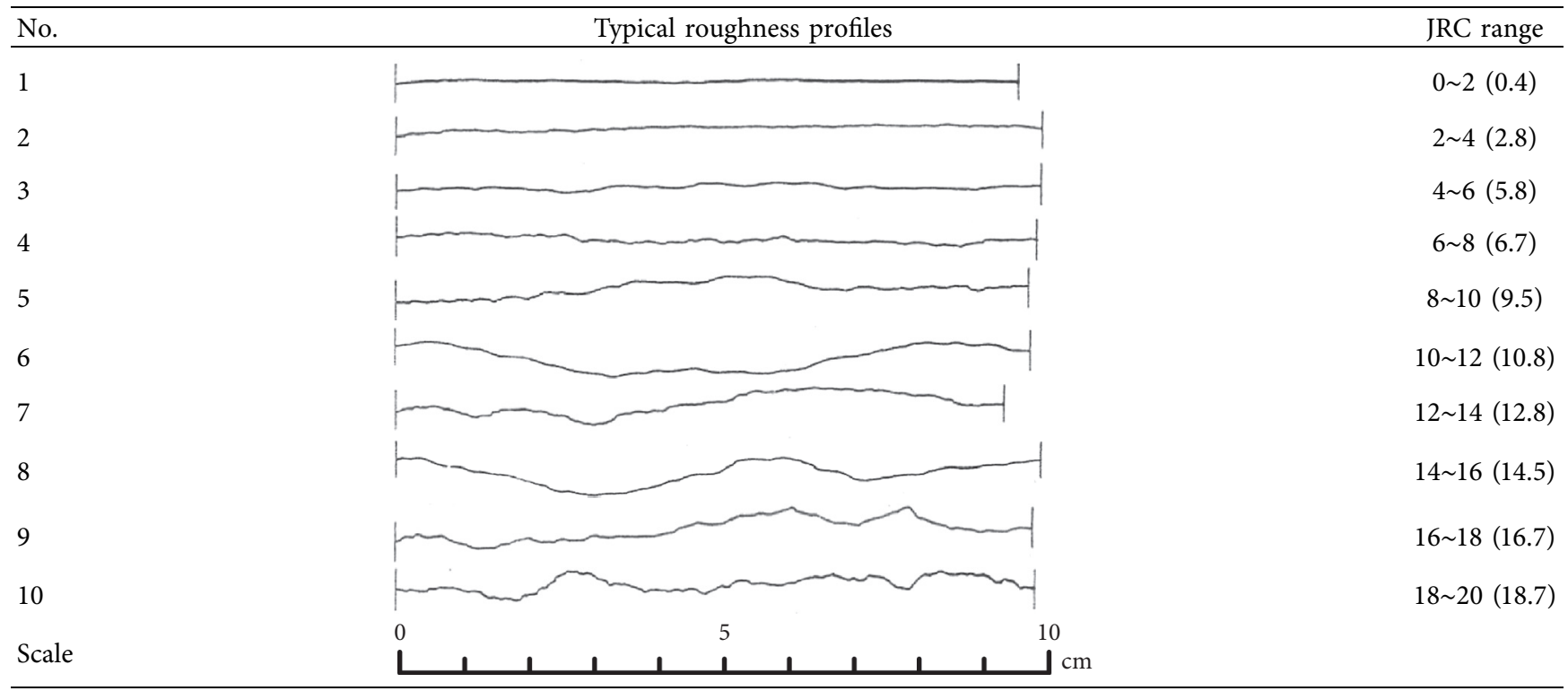

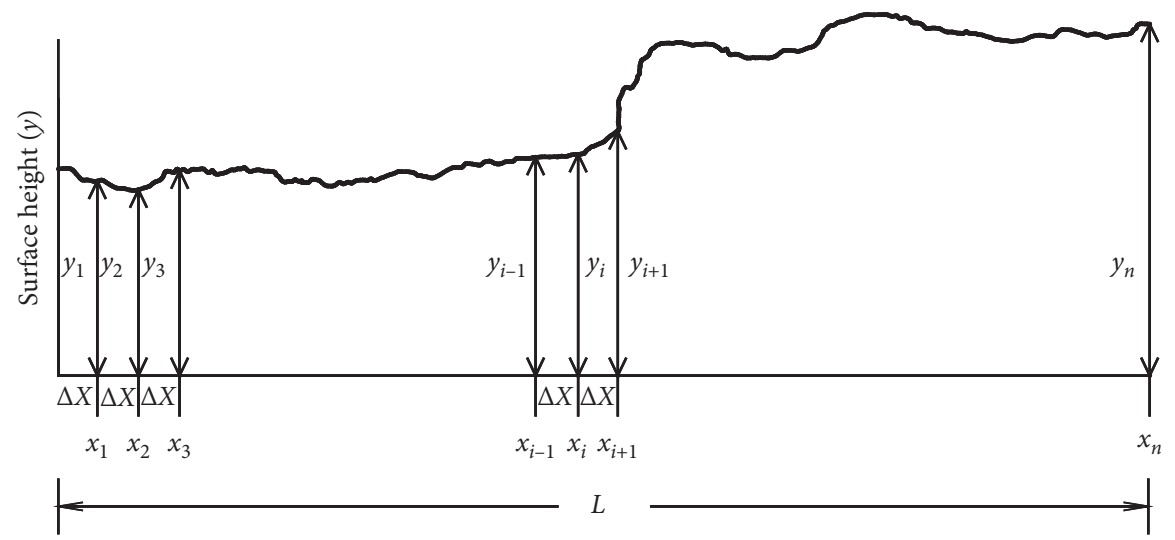

Figure 1: The diagram used to define geometric coordinates of a joint profile [26].

characterize the area (i.e., the size) of the microprotrusion. The area $A_{i}$ of the $i$-th microprotrusion could be calculated by

$$
A_{i}=\frac{\Delta x\left(h_{i+1}-h_{i}\right)}{2} .
$$

In existing studies, the inclination angle of joint protrusion had been proved to have a great influence on the shear failure mechanism, and its physical significance was very clear $[36,37]$. Therefore, the local inclination angle $\theta$ was selected to describe the surface roughness of the microjoint segment, which could be calculated from the geometric coordinates of the local joint profile, as shown in

$$
\theta=\tan ^{-1}\left(\frac{y_{i+1}-y_{i}}{x_{i+1}-x_{i}}\right) \text {. }
$$

When $\theta$ is positive, it indicates that the corresponding microjoint segment is oriented to the shear direction. On the contrary, when $\theta$ is negative, it indicates that the corresponding microjoint segment is in the direction of back shear. Based on the definition of microprotrusion, we assumed that the larger the microprotrusion size, the greater the contribution of surface roughness of microjoint segment to the overall roughness of joint profile. Therefore, the weight coefficient $\gamma_{i}$ was defined to represent the contribution of $i$-th microjoint roughness and it could be calculated by

$$
\gamma_{i}=\frac{A_{i}}{\sum_{i=1}^{i=n} A_{i}} .
$$

In equation (4), $n$ represents the number of all microjoint segments. The overall roughness $R_{i}$ of $i$-th microjoint segment could be expressed by the product of surface roughness $\theta_{i}$ and weight coefficient $\gamma_{i}$, as shown in

$$
R_{i}=\theta_{i}^{*} \gamma_{i}
$$

From the available joint shear test results, we knew that contact and extrusion of the joint surface occurred only at 


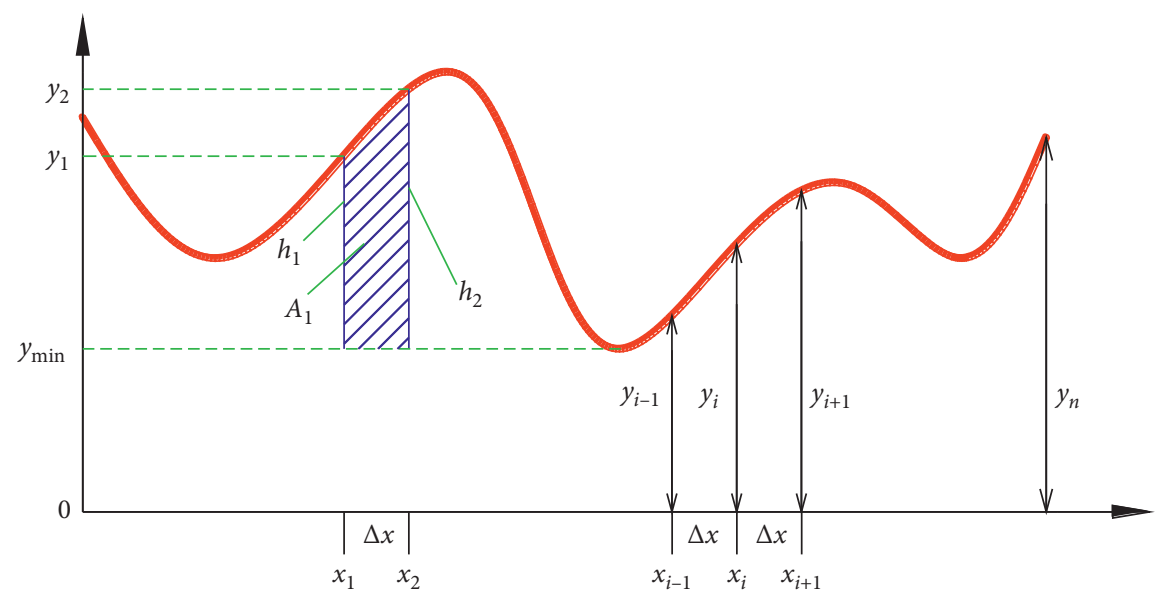

Figure 2: Schematic diagram of the area at microjoint segment.

the position facing the shear direction during the shear process. Therefore, referring to the treatment of Zhang et al. [24] and Belem et al. [25], when describing the roughness of joint profile along a certain shear direction, only the morphological data oriented to the shear direction were counted and involved in the roughness description. Considering the directionality of the shear process, the overall roughness $R_{i}$ data of microjoint segment greater than 0 were recorded as $R_{i}+$. The newly proposed statistical parameter WPA (the weighted positive angle) for describing joint roughness in this paper could be obtained by summing all the values of $R_{i}+$, as shown in equation (6), where $m$ represents the number of $R_{i}+$.

$$
\mathrm{WPA}=\sum_{i=1}^{i=m} R_{i}^{+}
$$

In the mathematical sense, the establishment of WPA is the process of calculating a weighted average of the local inclination angle $\theta_{i}$ of the microjoint segment. In the physical sense, the dual effects of protrusion size and shear direction on the joint roughness are considered simultaneously in the definition of WPA, which can reflect the shear destruction mechanism of the joint surface to some extent. Therefore, the new statistical parameter WPA can not only reflect the shear direction of joints but also reflect the contribution of different protrusions to the overall roughness. This makes it possible to establish an important relationship between the roughness description and the shear mechanism of rock joints, which is rarely considered by the existing statistical parameters such as $Z_{2}$ and $R_{P}$.

\section{Preparation for Research}

3.1. Digitization of Barton's Joint Profiles. In the currently available literature, the original version of the 10 standard roughness joint profiles originated from a journal paper published by Barton in 1977 [9]. Since the authors did not provide the raw data of the 10 joint profiles for the reader to review, later researchers could only obtain the geometric coordinates of the 10 joint profiles in the image with the help of various indirect methods.

The initial data acquisition process for the 10 standard roughness joint profiles proposed by Barton was based on a profile comb (Figure 3). The sampling interval (SI) of the initial data is $0.5 \mathrm{~mm}$ because the spacing between the comb teeth is about $1 \mathrm{~mm}$. The digitization of the 10 joint profiles using indirect methods is equivalent to the reacquisition of the original data, so the accuracy of our acquired data is limited by the accuracy of the original data. Therefore, the sampling interval for the digitizing process of the joint profile was set to $0.5 \mathrm{~mm}$ in this paper, and discrete data with larger sampling intervals could be obtained by an interpolation process.

In this paper, the image recognition method was chosen to complete the digitization of the joint profiles, and the image processing software was chosen to be GETDATA. We firstly used screenshot software to capture the image of each joint profile and saved it separately as a jpg image file. Before the data acquisition process, we also needed to remove useless pixels from the joint image and set the horizontal and vertical axes for it. The average horizontal length of 10 standard roughness joint profiles was about $99 \mathrm{~mm}$, which was close to $100 \mathrm{~mm}$. Among them, the 7 th profile was the shortest $(96 \mathrm{~mm})$ and the 8 th profile was the longest $(101 \mathrm{~mm})[8,21]$. According to the processing idea of Zheng and Qi [22], the horizontal length of the 10 joint profiles was assumed to be $100 \mathrm{~mm}$, and the JRC values of them were assumed to be unchanged. After that, the geometric coordinates of the joint profile could be obtained through the automatic acquisition mode and point capture mode. The data point was at the center of the joint profile by default. This process was similar to Jang et al. [21], as shown in Figure 4, and the modified 10 standard roughness joint profiles are shown in Figure 5.

3.2. Validation of Joint Profile Data. In order to verify the accuracy of joint profile data obtained in Section 3.1, statistical parameters $Z_{2}$ and $R_{P}-1$ that were widely used in 


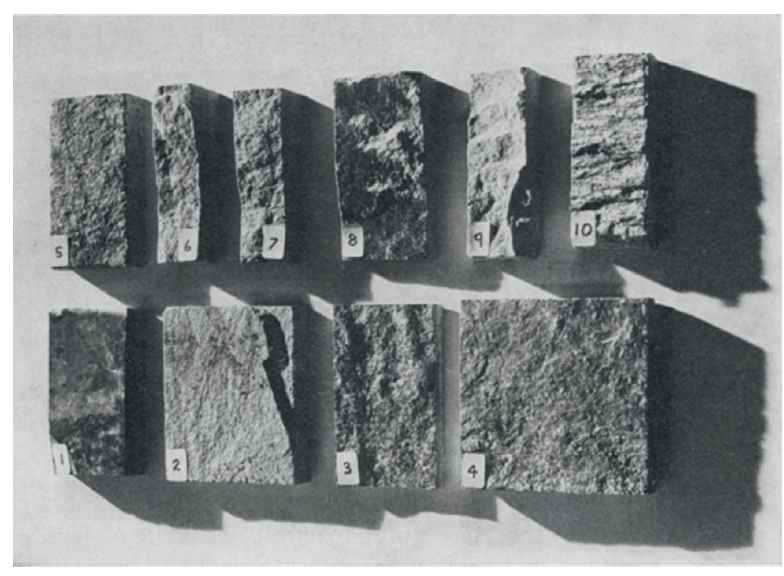

(a)

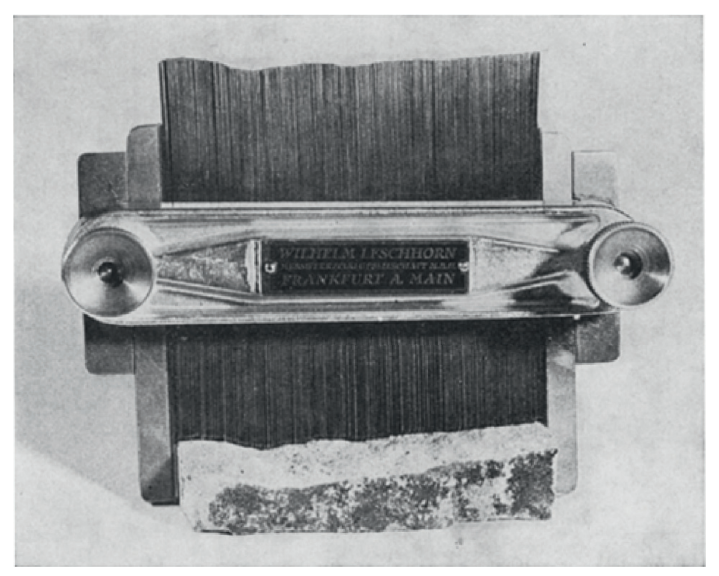

(b)

Figure 3: Procedure of using a profile comb to get a profile from the joint surface. (a) 10 typical joint surfaces. (b) Profile comb [8, 9].
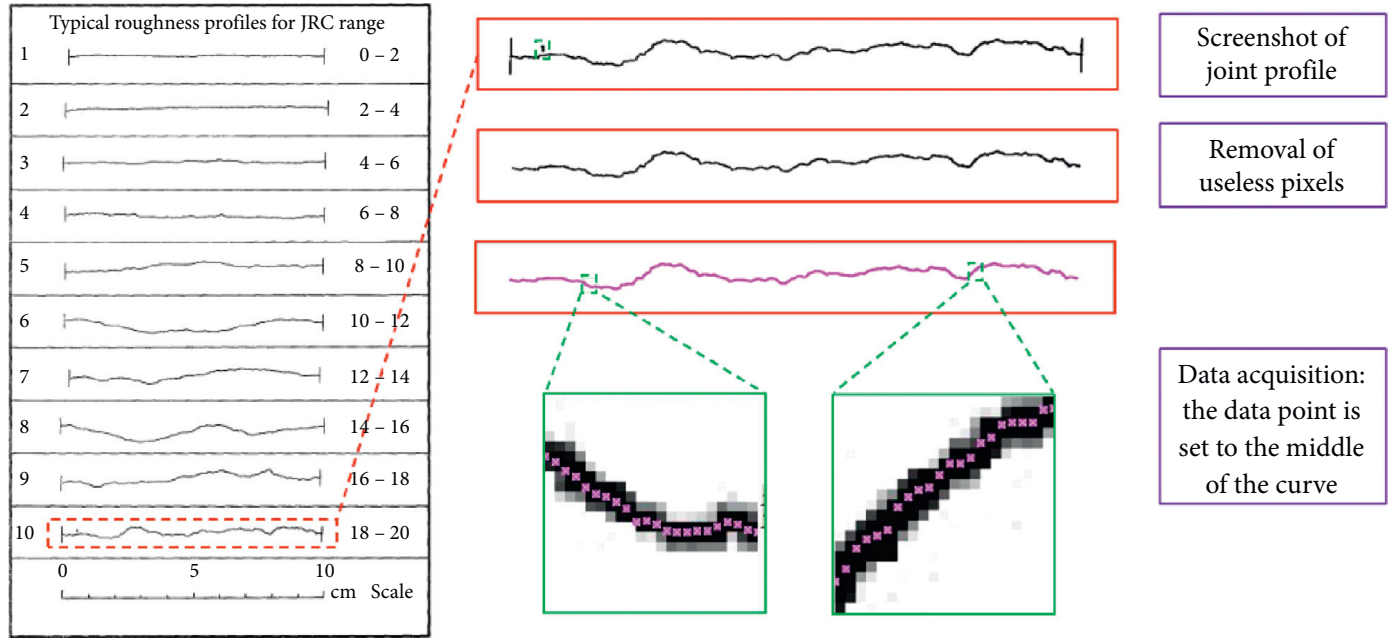

FIGURE 4: The diagram used to show the digitization of a joint profile.

actual engineering were recommended as representative for verification. Their definitions are as follows [17-23]:

$$
\begin{aligned}
Z_{2} & =\left[\frac{1}{L} \int_{x=0}^{x=L}\left(\frac{\mathrm{d} y}{\mathrm{~d} x}\right)^{2} \mathrm{~d} x\right]^{1 / 2}=\left[\frac{1}{(N-1)(D x)^{2}} \sum_{i=1}^{N-1}\left(y_{i+1}-y_{i}\right)^{2}\right]^{1 / 2}, \\
R_{p}-1 & =\frac{\sum_{i=1}^{N-1}\left[\left(x_{i+1}-x_{i}\right)^{2}+\left(y_{i+1}-y_{i}\right)^{2}\right]^{1 / 2}-1}{L},
\end{aligned}
$$

where $N$ is the number of discrete points in joint profile and it is 201 at $0.5 \mathrm{~mm}$ sampling interval. Under the condition of $0.5 \mathrm{~mm}$ sampling interval, the values of $Z_{2}$ and $R_{P}-1$ of ten standard roughness joint profiles were calculated, and their fitting relationship with JRC was established by

$$
J R C=a * \ln (P)+b,
$$

where $P$ represents the statistical parameters and $a$ and $b$ represent the regression coefficients. As shown in Figure 6, the values of $Z_{2}$ and $R_{P}-1$ were showing a growth trend with the increase of the JRC value. The correlation coefficients squared of $Z_{2}$ and $R_{P}-1$ with JRC calculated in our paper all exceeded 0.95 , which was like the findings of other researchers [17-23]. This confirmed that the data acquisition 


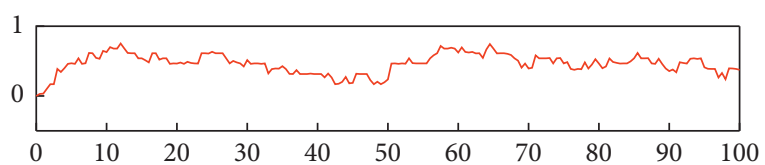

(a)

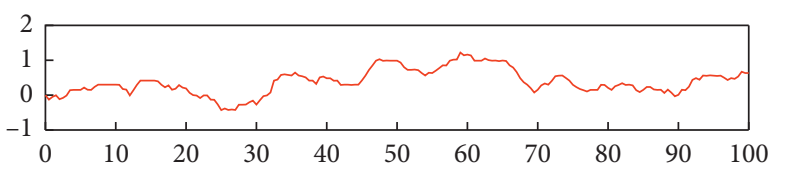

(c)

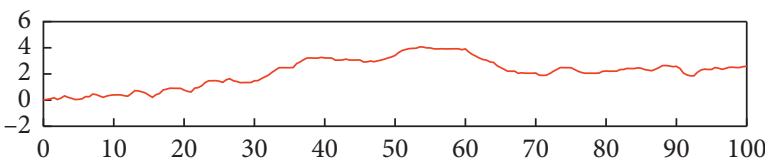

(e)

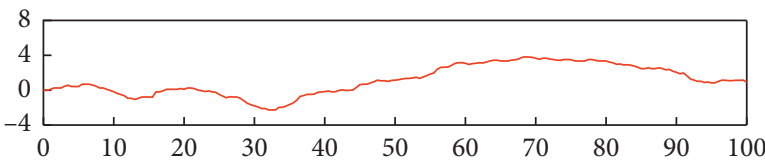

(g)

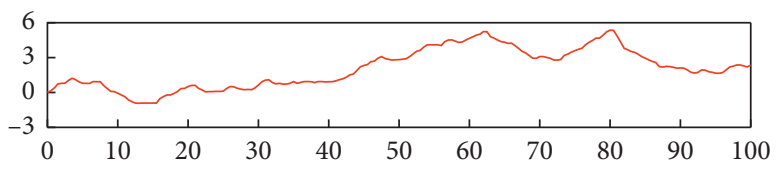

(i)

Figure 5: The modified 10 standard roughness profiles (unit: mm). (a) Profile 1. (b) Profile 2. (c) Profile 3. (d) Profile 4. (e) Profile 5. (f) Profile 6. (g) Profile 7. (h) Profile 8. (i) Profile 9. (j) Profile 10.

work of the Barton standard profiles in our paper was very accurate, and follow-up studies based on these acquired data were reliable.

\section{Validation of Correlation between WPA and JRC}

Based on the coordinate data of 10 standard roughness joint profiles obtained before, the WPA of each joint profile under two shear directions was obtained according to the calculation process from equation (2) to equation (6). The calculation results of WPA are summarized in Table 2, and the corresponding sampling interval was set to $0.5 \mathrm{~mm}$. For the convenience of subsequent description, shearing from left to right was noted as direction 1 , and shearing from right to left was noted as direction 2 .

At $0.5 \mathrm{~mm}$ sampling interval, each joint profile contains 200 microjoint segments; however, the number of microsegments involved in the calculation was not the same in direction 1 and direction 2 . In direction 1, the WPA values of the joint profile increased consistently with the corresponding number. In direction 2, although the WPA values of the joint profile increased with the corresponding number as a whole, there were anomalies in the fifth and seventh joint profiles.

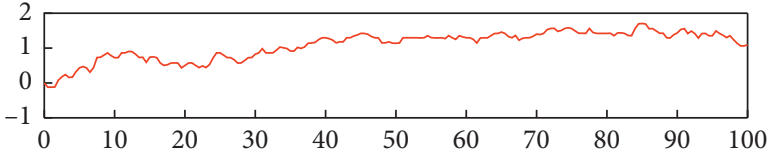

(b)

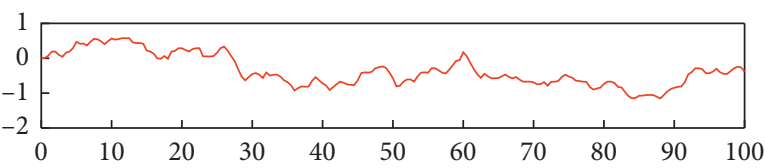

(d)

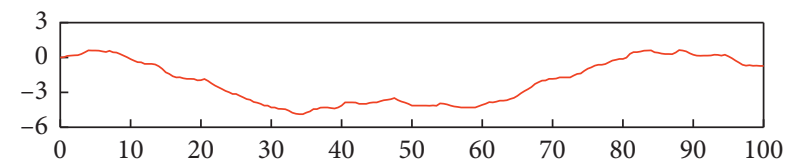

(f)

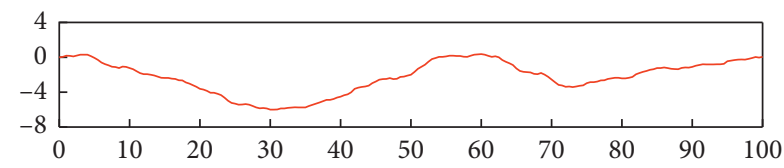

(h)

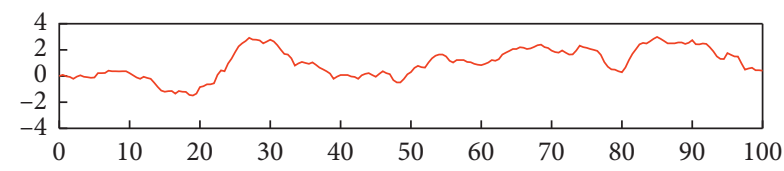

(j)

To validate the rationality of WPA when describing joint profile roughness, the functional relationships between WPA and JRC for different joint profiles in two shear directions were established in the same form as equation (3). As can be seen in Figure 7 and equations (9) and (10), the correlation between WPA and JRC of joint profile in direction 1 was better than that in direction 2 , and the square of correlation coefficient $\left(R^{2}\right)$ is 0.9643 and 0.8883 , respectively.

$$
\begin{aligned}
\mathrm{JRC}= & 14.602 \ln (\mathrm{WPA})-12.536 \\
R^{2}= & 0.9643 \\
& \text { direction } 1 \\
\mathrm{JRC}= & 13.502 \ln (\mathrm{WPA})-10.308 \\
R^{2}= & 0.8883 \\
& \text { direction } 2 .
\end{aligned}
$$

It is worth noting that this phenomenon is a good verification of the directionality of the joint roughness. When Barton proposed the 10 standard rough joint profiles, the default shear direction was from left to right [8]. So, the attached JRC values in Table 1 only represented the roughness of the joint profiles in direction 1 rather than 


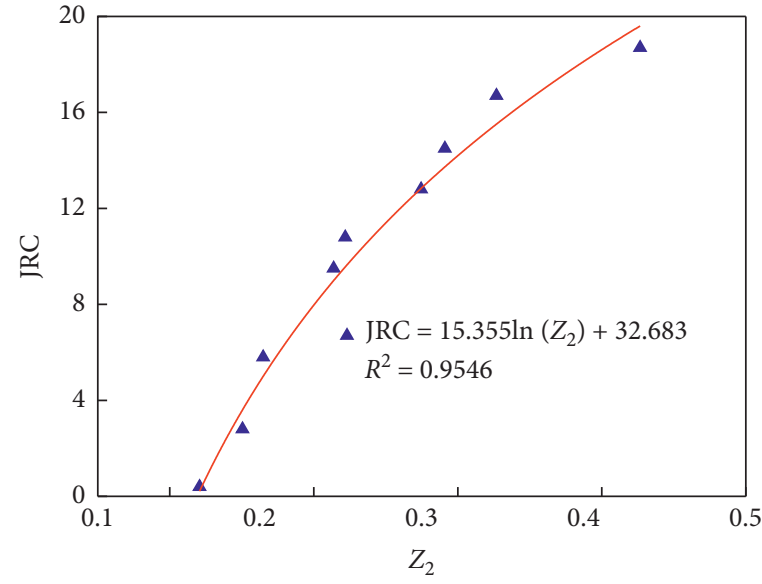

(a)

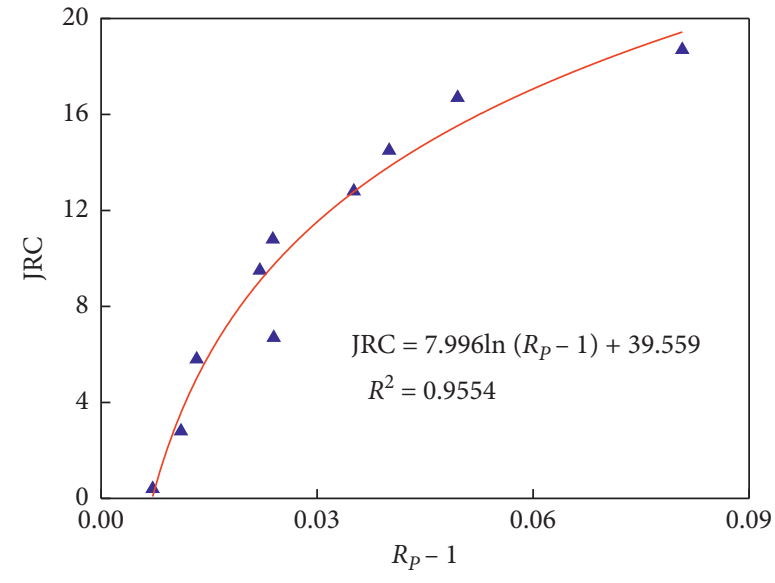

(b)

Figure 6: Fitting curves between statistical parameters and JRC. (a) $Z_{2}$. (b) $R_{P}-1$.

TABLE 2: The WPA values of 10 joint profiles in different directions $(\mathrm{SI}=0.5 \mathrm{~mm})$.

\begin{tabular}{|c|c|c|c|c|}
\hline \multirow{2}{*}{ Number of joint profiles } & \multicolumn{2}{|c|}{ Direction 1} & \multicolumn{2}{|c|}{ Direction 2} \\
\hline & WPA & $\mathrm{m}$ & WPA & $\mathrm{m}$ \\
\hline 1 & 2.35 & 84 & 2.29 & 116 \\
\hline 2 & 3.11 & 97 & 2.79 & 103 \\
\hline 3 & 3.42 & 87 & 3.13 & 113 \\
\hline 4 & 4.35 & 88 & 4.97 & 112 \\
\hline 5 & 4.43 & 102 & 3.55 & 98 \\
\hline 6 & 4.50 & 90 & 5.16 & 110 \\
\hline 7 & 5.18 & 97 & 4.87 & 103 \\
\hline 8 & 6.17 & 104 & 6.09 & 96 \\
\hline 9 & 7.87 & 105 & 6.74 & 95 \\
\hline 10 & 8.47 & 89 & 8.50 & 111 \\
\hline
\end{tabular}

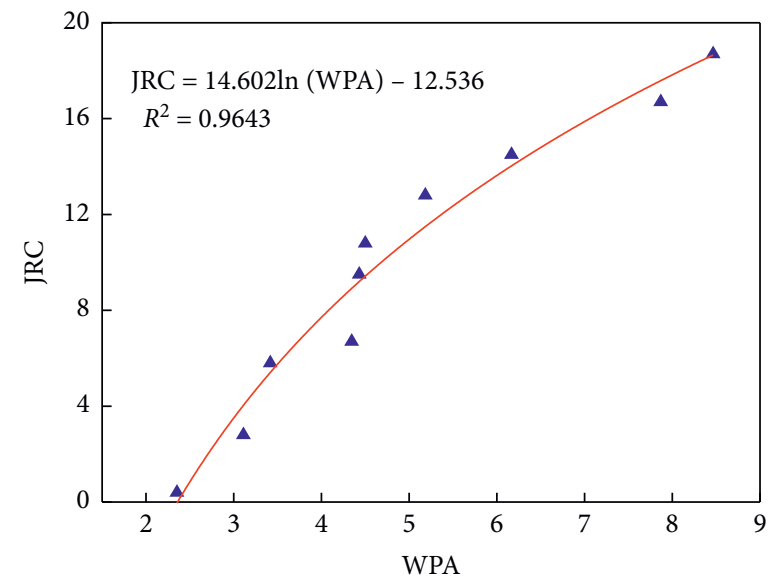

(a)

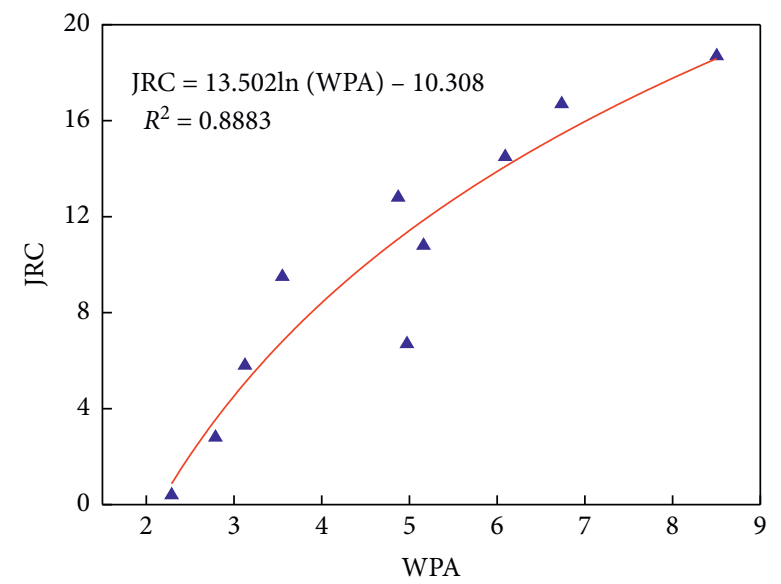

(b)

FIgURE 7: The functional relationships between WPA and JRC in two shear directions. (a) Direction 1. (b) Direction 2.

direction 2. As the data used in Figure 7(b) were based on different shear directions, so this showed that the joint roughness is directional. In summary, the functional relationship between the statistical parameters and the JRC should be established in the same shear direction; otherwise, large errors will occur such as those shown in Figure 7(b). 
Based on the above analysis, equation (9) was proposed to estimate the JRC of the joint profile at a sampling interval of $0.5 \mathrm{~mm}$. Therefore, when we substitute the WPA values of 10 joint profiles in direction 2 into equation (9), the JRC values of 10 joint profiles in direction 2 can be obtained successfully. Table 3 shows the JRC values of 10 standard roughness joint profiles in two directions.

As can be seen from Table 3, the JRC values of 10 standard roughness joint profiles in two shear directions were verified to be different, which was consistent with the results obtained by Zheng and Qi [22]. Among them, the absolute difference of JRC in two directions of the fourth joint profile was the largest (4.18), and that of the tenth joint profile was the smallest (0.01). For the first joint profile, its JRC in direction 2 was negative, and this exceeded the limit where the minimum JRC value was 0 . So, in order to keep the estimated JRC value of joint profiles in the normal range, the range of WPA should be larger than 2.35 965. In direction 2, the order of JRC sizes for the 10 standard roughness profiles had changed, as shown at the 4 th, 5 th, $6^{\text {th }}$, and 7 th joint profiles.

\section{Effect of Sampling Interval on WPA}

In actual rock engineering, the accuracy of the joint surface data is greatly influenced by the sampling method and equipment, so the sampling interval varies widely. When the statistical parameter method is used to predict the roughness, the sampling interval conditions of joint profile data, statistical parameters, and corresponding function relationship must be consistent to ensure the correctness of this work $[21,22]$. Therefore, in order to expand the application range of the new statistical parameters, the functional relationships between WPA and JRC were established under various sampling intervals. In Section 3.1, the geometric coordinate data of 10 standard roughness joint profiles were obtained at a $0.5 \mathrm{~mm}$ sampling interval. On this basis, the coordinate data of 10 joint profiles at sampling intervals of 1 , 2,4 , and $10 \mathrm{~mm}$ could be easily obtained by interpolation.

In direction 1, the WPA values of 10 standard roughness joint profiles at 5 sampling intervals are shown in Table 4, and their variation with sampling interval is shown in Figure 8 . It can be seen that the sampling interval had a great influence on the WPA values of joint profiles. With the increase of sampling interval from $0.5 \mathrm{~mm}$ to $10 \mathrm{~mm}$, the WPA values of each joint profile decreased gradually, and the decreasing speed was first large and then small. In practical application, the sampling interval condition should be clarified to avoid confusion.

At sampling intervals of $1,2,4$, and $10 \mathrm{~mm}$, the relationship curve and functional relationship between WPA and JRC of 10 joint profiles are given in Figure 9. We can see that the JRC of the joint profile kept a positive correlation with WPA under all sampling interval schemes. For the convenience of description, the fitting formulas between WPA and JRC under different sampling intervals are summarized in Table 5. It can be seen that the $R^{2}$ of the fitting formulas between WPA and JRC decreased from 0.9643 to 0.9311 with the increase of sampling interval from $0.5 \mathrm{~mm}$ to
$10 \mathrm{~mm}$. Overall, as the sampling interval increased, the correlation of the functional relationship between WPA and JRC decreased. This is because there must be an error between the obtained joint profile and the original joint profile, and this error increases as the sampling interval increases.

Figure 10 shows a comparison of the 10th joint profile obtained at $0.5 \mathrm{~mm}$ and $10 \mathrm{~mm}$ sampling intervals. The morphology of the joint profile obtained at the two sampling intervals was quite different. When the sampling interval changes from $0.5 \mathrm{~mm}$ to $10 \mathrm{~mm}$, the sampling points of the joint profile decreased from 201 to 11 and many local rough features had been lost. Therefore, the WPA obtained from the joint profile data of the $10 \mathrm{~mm}$ sampling interval could not reflect the morphological characteristics of the original joint very well. This indicated that when we want to predict the roughness of the original joint profile, the sampling interval should be as small as possible; otherwise, the prediction accuracy will be reduced.

\section{Validation of the WPA's Applicability}

In order to show the advantage of WPA in predicting the JRC of the joint profile, we separately evaluated the roughness of the joint profile given in the literature and the natural joint surface.

\subsection{JRC Estimation of the Joint Profiles Given in the Literature.} Firstly, we performed the corresponding digitization process in Section 3.1 on the joint profile given in the literature $[18,24,38-41]$ at the sampling interval of $0.5 \mathrm{~mm}$. Next, the WPA and corresponding JRC values of 21 joint profiles were calculated through equation (2) to equation (6) in two shear directions, as shown in Table 6.

The results showed that the JRC of these joint profiles was in 2 shear directions, where the difference of JRC of the 7 th joint profile in two directions was as high as 25.4. Besides, the JRC of the 6 th and 7 th joint profiles in direction 1 had exceeded Barton's upper limit of 20. This indicated that the new statistical parameter WPA not only can well reflect the rough morphology but also can distinguish the differences of roughness in different shear directions. This cannot be achieved with the visual contrast method or the previous statistical parametric without considering directionality.

6.2. JRC Estimation of the Natural Joint Surface. The 4 joint specimens used to evaluate roughness were collected from Taibai Mountain, Xi'an City, Shaanxi Province, China. As shown in Figure 11, the rock type is granite and the plane size is about $100 \mathrm{~mm} \times 100 \mathrm{~mm}$. The jointed surfaces of these specimens were produced by artificial load damage at the quarry and they were all not weathered.

The 3D point cloud data of 4 joint specimens were obtained by $3 \mathrm{D}$ scanner go! Scan 20 , and then, they were imported into Geomagic Studio software. Firstly, the point cloud data were denoised, and then the coordinate system correction is completed. Finally, the joint surface data are separated, as shown in Figure 12. 
TABLE 3: Comparison of JRC values in different directions for 10 standard roughness joint profiles.

\begin{tabular}{lccc}
\hline Number of joint profiles & & JRC values & Absolute difference \\
\hline 1 & Direction 1 & Direction 1 & 0.84 \\
2 & 0.4 & -0.44 & 0.35 \\
3 & 2.8 & 2.45 & 1.67 \\
4 & 5.8 & 4.13 & 4.18 \\
5 & 6.7 & 10.88 & 3.54 \\
6 & 9.5 & 5.96 & 0.62 \\
7 & 10.8 & 11.42 & 2.22 \\
8 & 12.8 & 10.58 & 0.66 \\
9 & 14.5 & 13.84 & 1.37 \\
10 & 16.7 & 15.33 & 0.01 \\
\hline
\end{tabular}

TABLE 4: The WPA values of 10 joint profiles at 5 sampling intervals.

\begin{tabular}{|c|c|c|c|c|c|}
\hline \multirow{2}{*}{ Number of joint profiles } & \multicolumn{5}{|c|}{ Sampling intervals $(\mathrm{mm})$} \\
\hline & 0.5 & 1 & 2 & 4 & 10 \\
\hline 1 & 2.35 & 1.64 & 1.15 & 0.75 & 0.58 \\
\hline 2 & 3.11 & 2.45 & 1.39 & 1.21 & 0.73 \\
\hline 3 & 3.42 & 2.87 & 2.57 & 1.95 & 1.42 \\
\hline 4 & 4.35 & 3.88 & 2.69 & 2.05 & 1.48 \\
\hline 5 & 4.43 & 4.03 & 3.75 & 3.10 & 2.37 \\
\hline 6 & 4.50 & 4.26 & 4.10 & 3.74 & 2.63 \\
\hline 7 & 5.18 & 4.44 & 3.96 & 3.50 & 2.16 \\
\hline 8 & 6.17 & 5.86 & 5.72 & 5.54 & 5.08 \\
\hline 9 & 7.87 & 7.58 & 6.99 & 6.19 & 5.54 \\
\hline 10 & 8.47 & 7.92 & 6.44 & 5.49 & 4.87 \\
\hline
\end{tabular}

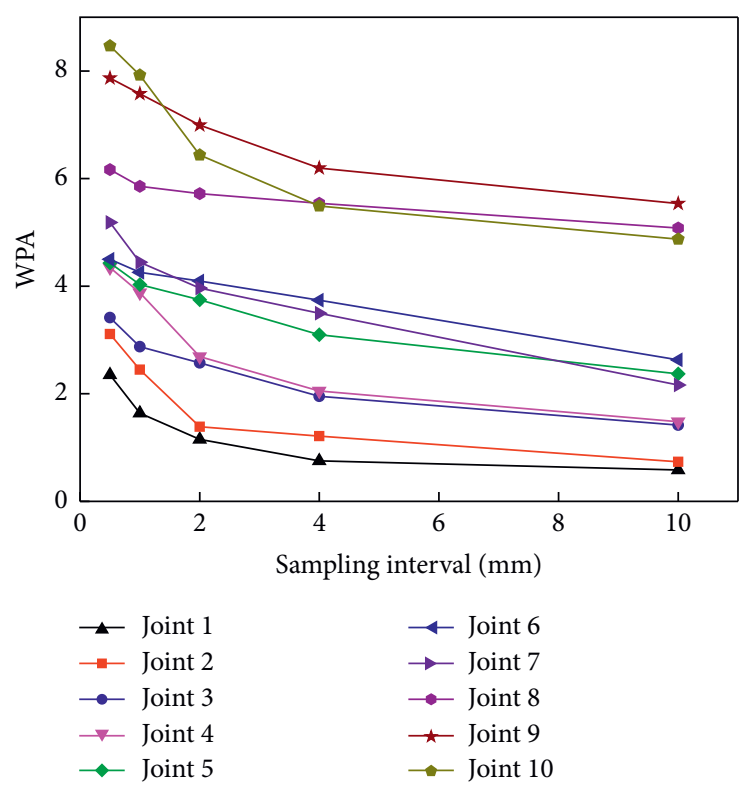

FIGURE 8: The effect of different sampling intervals on WPA values of 10 standard roughness joint profiles.

In this section, the roughness of the joint surface in different directions was represented by the roughness of the joint profile. The data of joint profile were obtained by Geomagic Studio software, and the acquisition method of joint profile data is shown in Figure 13. The interval of joint profiles on the joint surface was $15^{\circ}$, and the number of joint profiles intercepted on each joint surface was 12 . Since the roughness of each joint profile could be analyzed in two directions, the roughness of the joint surface could be described in 24 directions.

The $3 \mathrm{D}$ coordinate data of all joint profiles were processed by Surfer software, and the 2D coordinate data with a 


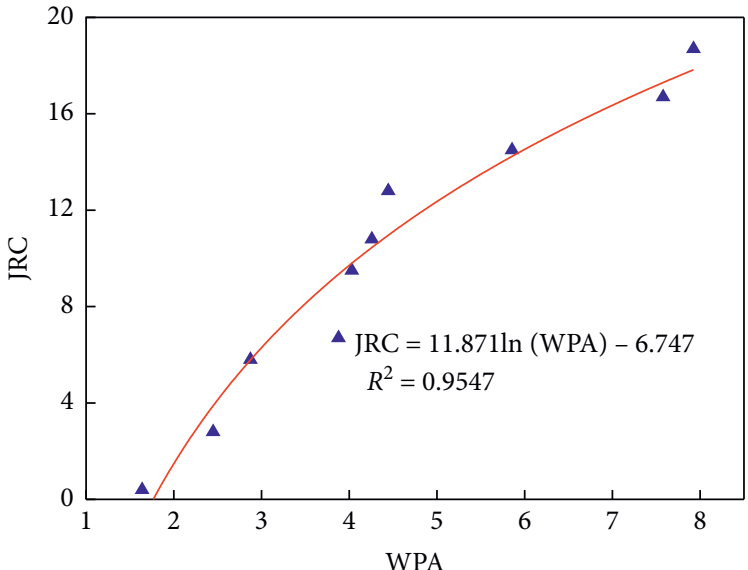

(a)

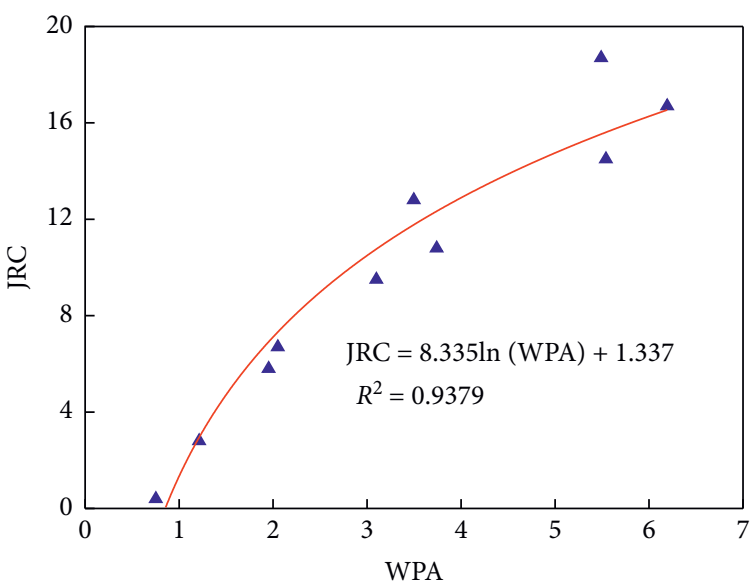

(c)

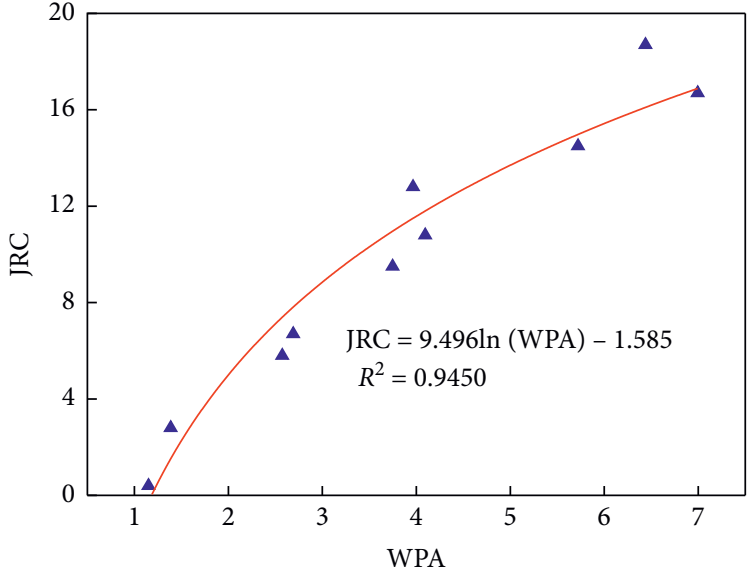

(b)

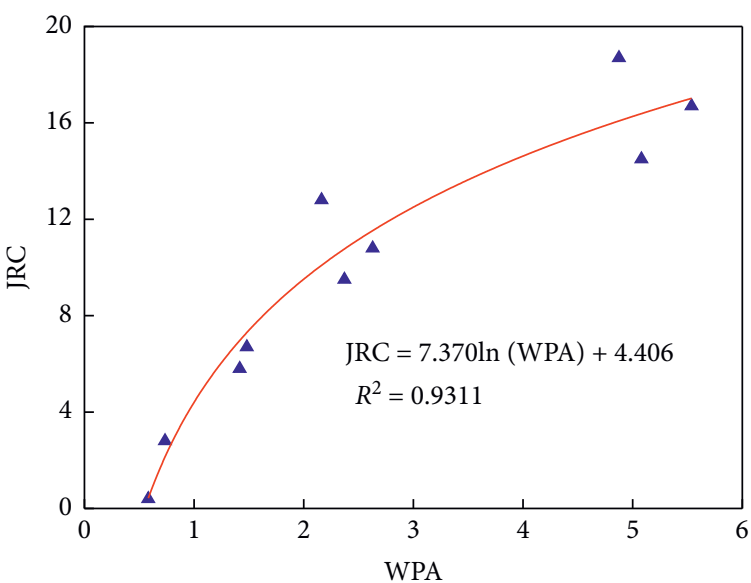

(d)

FIGURE 9: The functional relationships between WPA and JRC under different sampling intervals. (a) $1 \mathrm{~mm}$. (b) $2 \mathrm{~mm}$. (c) $4 \mathrm{~mm}$. (d) $10 \mathrm{~mm}$.

TABLE 5: The fitting formulas between WPA and JRC under different sampling intervals.

\begin{tabular}{lcr}
\hline Sampling interval $(\mathrm{mm})$ & Functional relationship & $R^{2}$ \\
\hline 0.5 & JRC $=14.602 \ln (\mathrm{WPA})-12.536$ & 0.9643 \\
1 & JRC $=11.871 \ln (\mathrm{WPA})-6.747$ & 0.9547 \\
2 & JRC $=9.496 \ln (\mathrm{WPA})-1.585$ & 0.9450 \\
4 & JRC $=8.335 \ln (\mathrm{WPA})+1.337$ & 0.9379 \\
10 & JRC $=7.370 \ln (\mathrm{WPA})+4.406$ & 0.9311 \\
\hline
\end{tabular}

$0.5 \mathrm{~mm}$ sampling interval were obtained. Then, the JRC values of these joint profiles in two directions were calculated using the new statistical parameter WPA, as shown in Figure 14.

It could be seen from Figure 14 that the JRC values of the four joint surfaces were different in 24 shear directions. Among them, the JRC of joint surface J-1 was the largest in $45^{\circ}$ direction and the minimum in $300^{\circ}$ direction. The JRC of joint surface J-2 was the largest in the $210^{\circ}$ direction and the minimum in the $150^{\circ}$ direction. The JRC of joint surface J-3 was the largest in $255^{\circ}$ direction and the minimum in $300^{\circ}$ direction. The JRC of joint surface J-4 was the largest in the $15^{\circ}$ direction and the minimum in the $240^{\circ}$ direction. The above results showed that the new statistical parameter WPA proposed in this paper can well reflect the anisotropy of the joint surface roughness. 


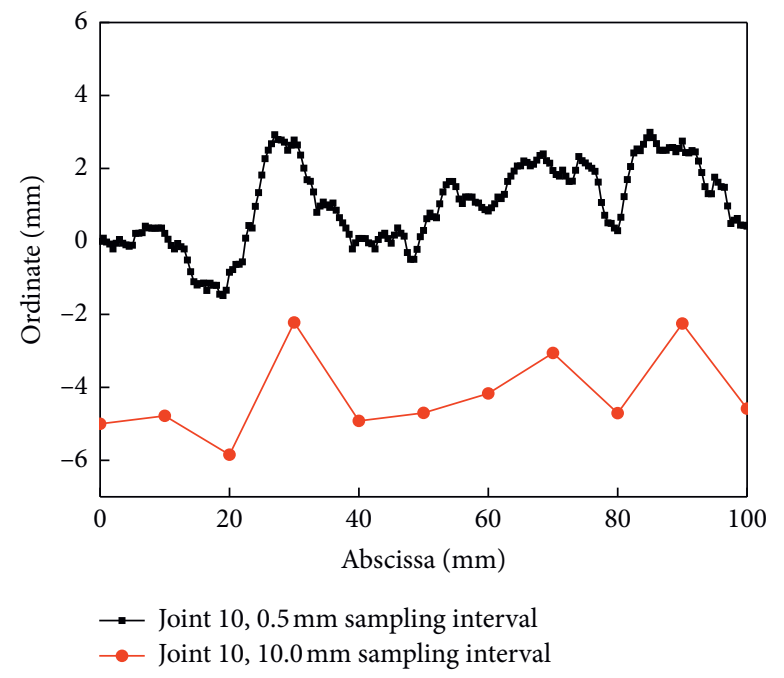

FIgURE 10: Comparison of the 10th joint profile obtained at $0.5 \mathrm{~mm}$ and $10 \mathrm{~mm}$ sampling intervals.

TABLE 6: The estimated JRC values of each joint profile using WPA.

\begin{tabular}{|c|c|c|c|c|c|c|c|}
\hline \multirow{2}{*}{ Reference } & \multirow{2}{*}{ No. } & \multirow{2}{*}{ Length (mm) } & \multirow{2}{*}{ JRC in literature } & \multicolumn{2}{|c|}{ WPA } & \multicolumn{2}{|c|}{ JRC } \\
\hline & & & & Direction 1 & Direction 2 & Direction 1 & Direction 2 \\
\hline \multirow[t]{3}{*}{ Yang [18] } & 1 & 50 & 13.18 & 5.10 & 5.37 & 11.24 & 12.00 \\
\hline & 2 & 100 & 13.33 & 5.10 & 5.37 & 11.24 & 12.00 \\
\hline & 3 & 200 & 13.46 & 5.10 & 5.37 & 11.24 & 12.00 \\
\hline Oding $[38]$ & 4 & 100 & $4-6$ & 3.83 & 3.31 & 7.08 & 4.95 \\
\hline Ozvan et al. [39] & 5 & 100 & 12 & 4.81 & 6.02 & 10.39 & 13.68 \\
\hline \multirow[t]{3}{*}{ Zhang et al. [24] } & 6 & 50 & 19.2 & 14.97 & 5.40 & 26.98 & 12.08 \\
\hline & 7 & 50 & 17.1 & 14.92 & 2.62 & 26.93 & 1.53 \\
\hline & 8 & 50 & 14.6 & 8.96 & 2.53 & 19.48 & 1.04 \\
\hline \multirow[t]{9}{*}{ Yong et al. [40] } & 9 & 100 & $14-16$ & 4.88 & 5.01 & 10.61 & 11.00 \\
\hline & 10 & 100 & $18-20$ & 5.82 & 9.17 & 13.18 & 19.81 \\
\hline & 11 & 100 & $14-16$ & 6.73 & 3.26 & 15.30 & 4.72 \\
\hline & 12 & 100 & $10-12$ & 5.22 & 2.67 & 11.58 & 1.80 \\
\hline & 13 & 100 & $6-8$ & 3.21 & 2.59 & 4.49 & 1.36 \\
\hline & 14 & 100 & $10-12$ & 4.25 & 2.92 & 8.59 & 3.12 \\
\hline & 15 & 100 & $4-6$ & 3.14 & 2.99 & 4.17 & 3.46 \\
\hline & 16 & 100 & $2-4$ & 2.76 & 2.45 & 2.29 & 0.55 \\
\hline & 17 & 100 & $2-4$ & 2.42 & 2.39 & 0.37 & 0.19 \\
\hline \multirow[t]{4}{*}{ Ye et al. [41] } & 18 & 170 & 7.704 & 3.21 & 2.87 & 4.49 & 2.88 \\
\hline & 19 & 170 & 8.007 & 3.25 & 2.52 & 4.67 & 0.96 \\
\hline & 20 & 170 & 7.955 & 3.18 & 2.41 & 4.37 & 0.31 \\
\hline & 21 & 170 & 6.331 & 4.55 & 2.53 & 9.57 & 1.02 \\
\hline
\end{tabular}

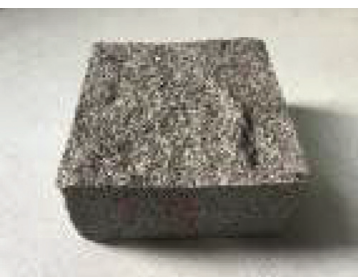

(a)

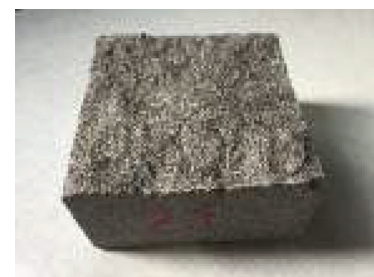

(b)

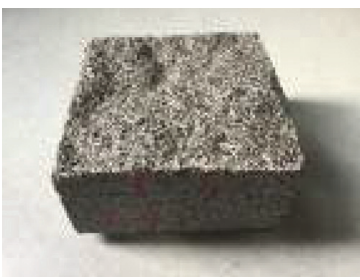

(c)

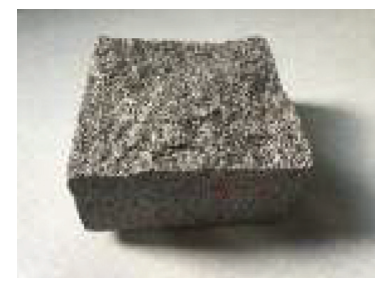

(d)

Figure 11: The 4 joint specimens used to evaluate roughness. (a) J-1. (b) J-2. (c) J-3. (d) J-4. 


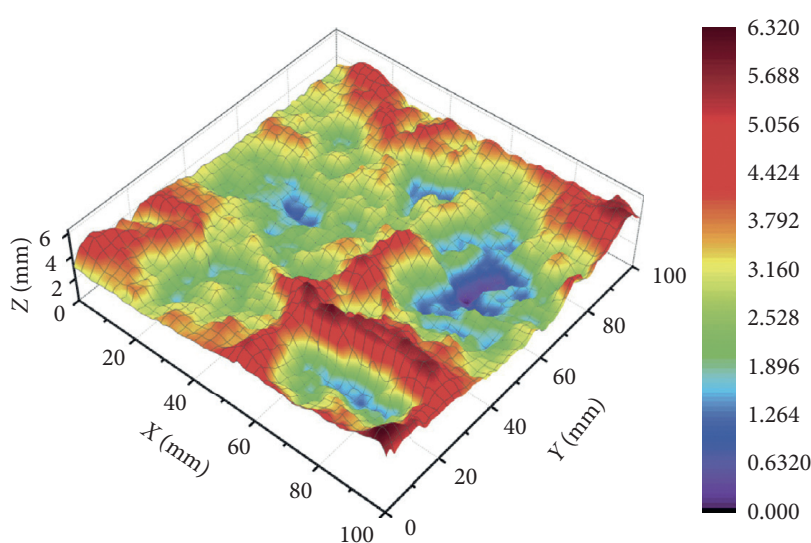

(a)

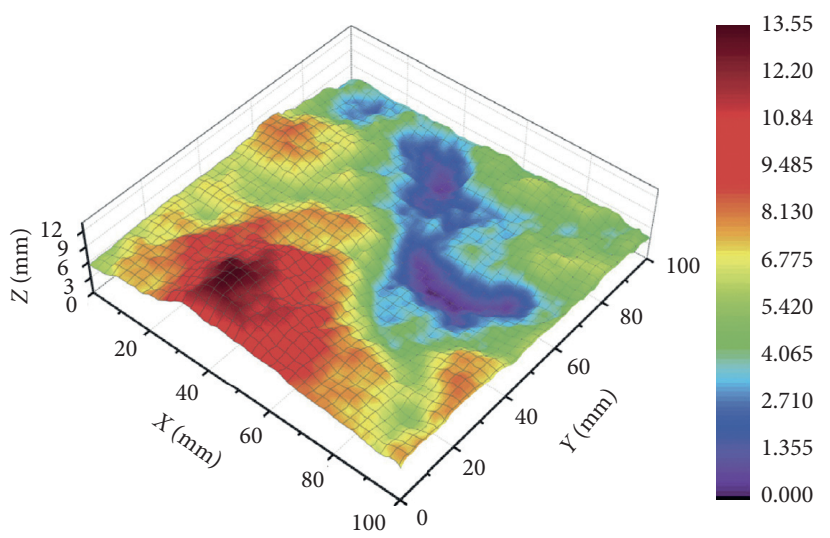

(c)

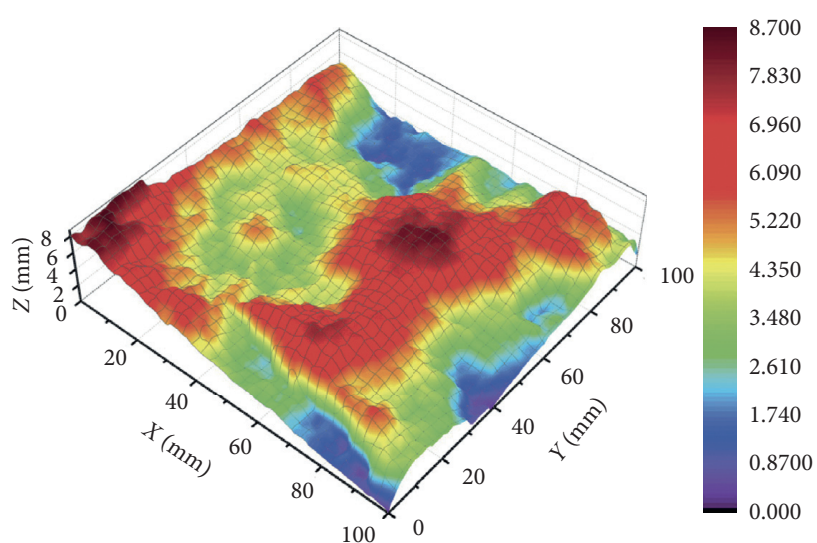

(b)

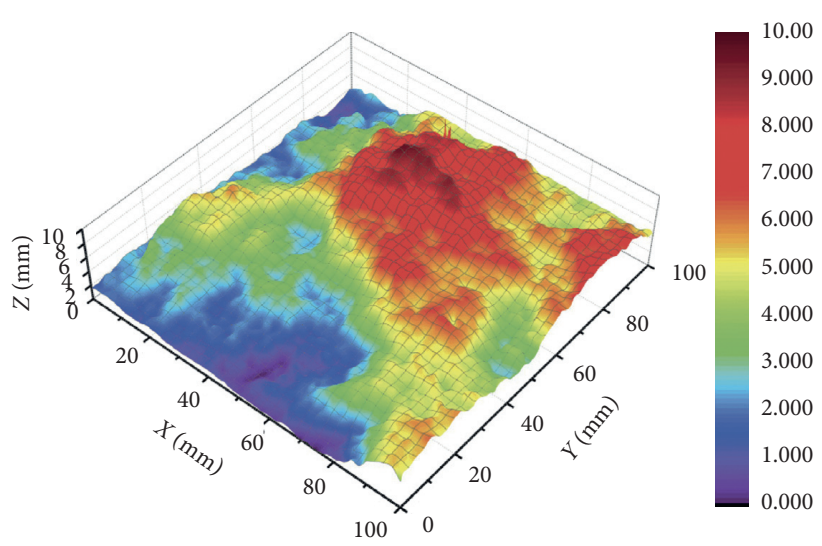

(d)

Figure 12: Schematic diagrams of 4 joint surface models. (a) Joint J-1. (b) Joint J-2. (c) Joint J-3. (d) Joint J-4.

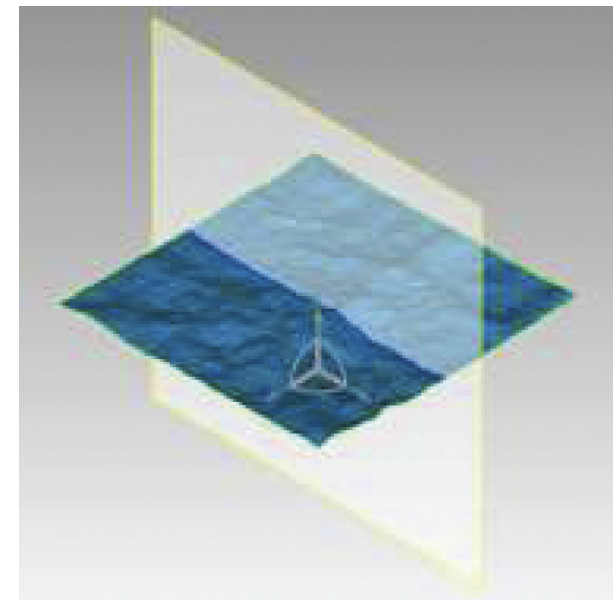

(a)

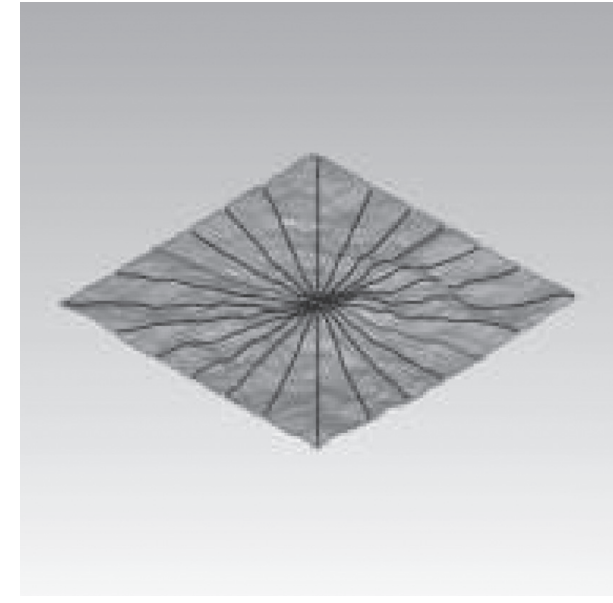

(b)

FIgURE 13: The acquisition method of joint profile data. (a) Interception of joint profiles through the system coordinate plane. (b) Location of 12 joint profiles on the joint surface. 


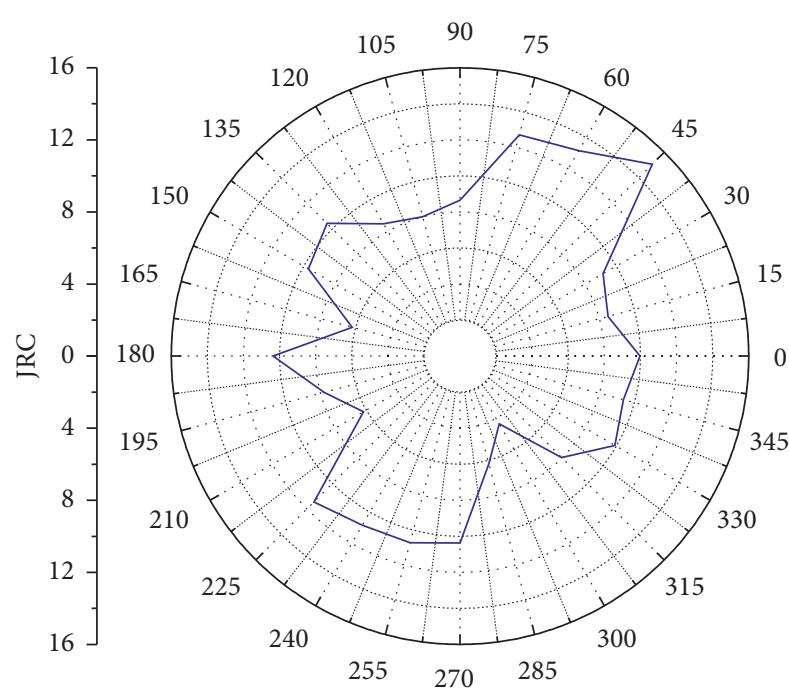

(a)

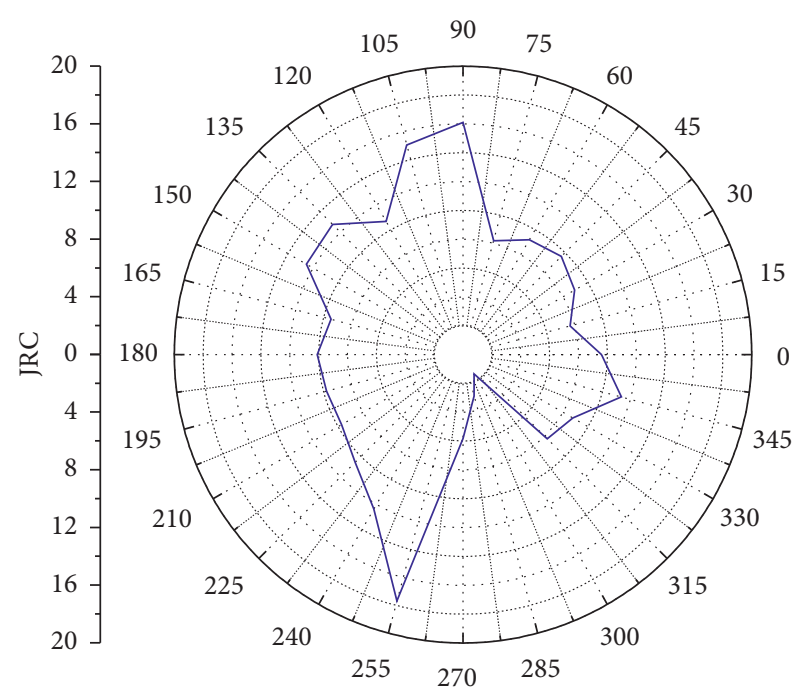

(c)

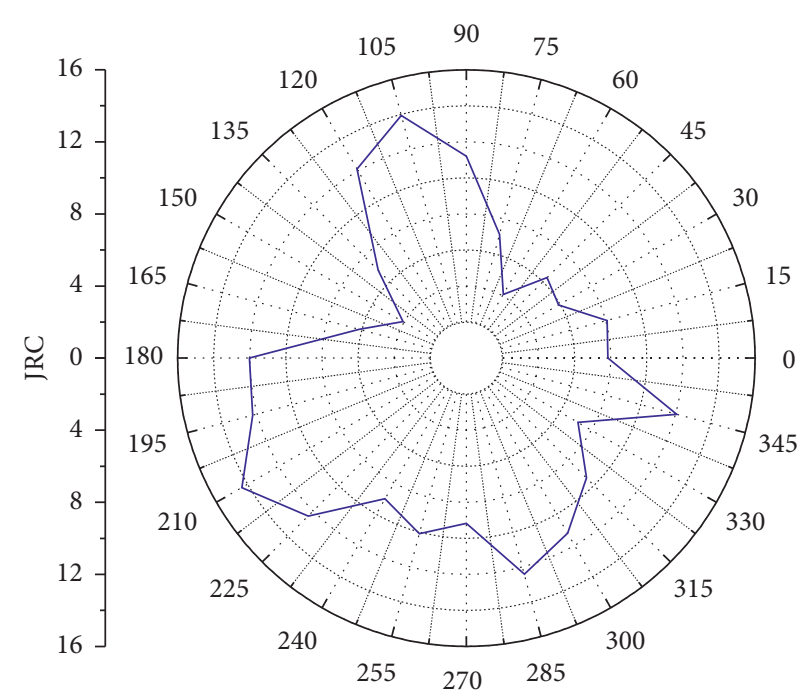

(b)

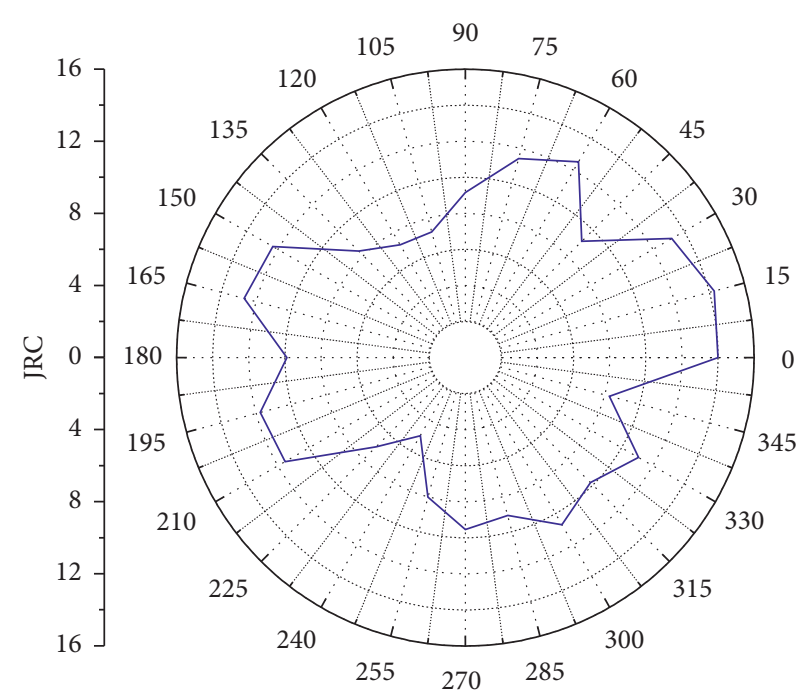

(d)

FIGURE 14: The JRC evaluation results of 4 joint surfaces in different directions. (a) Joint J-1. (b) Joint J-2. (c) Joint J-3. (d) Joint J-4.

\section{Conclusion}

In order to predict the shear strength of rock joints, a new statistical parameter WPA was proposed to estimate the joint roughness coefficient (JRC) of the joint profile in this paper. In the definition of WPA, the contribution degrees of different protrusions on joint profile and shear direction were well considered. First, we assumed that the larger the microprotrusion size, the greater the contribution of surface roughness of microjoint segment to the overall roughness of joint profile. Second, only the morphological data oriented to the shear direction were counted and involved in the roughness description. This provided a good response to the shear failure mechanism of the joint surface.

The 10 standard roughness joint profiles proposed by Barton were digitized using data processing software, and the currently widely used statistical parameters $Z_{2}$ and $\mathrm{R}_{P}-1$ were calculated based on the acquired coordinate data. The results showed that the correlation between $Z_{2}$ and $\mathrm{R}_{P}-1$ and JRC was consistent with previous studies, which suggested that the digitization process of the joint profiles in this paper was reliable.

At $0.5 \mathrm{~mm}$ sampling intervals, the WPAs of the 10 standard roughness joint profiles in two shear directions were calculated, and their functional relationships with the JRC values were established separately. The results showed that the correlation between WPA and JRC calculated in direction 1 was higher than that in direction 2 , and this well reflects the directivity of joint roughness. On this basis, the JRCs of the 10 standard roughness joint profiles in direction 2 were calculated and their size and order are different from those of direction 1.

The sampling interval of joint profile data had been confirmed to have a strong influence on both the WPA value and their correlation with JRC. As the sampling interval increased from $0.5 \mathrm{~mm}$ to $10 \mathrm{~mm}$, the WPA values of each 
joint profile gradually decreased, and the $R^{2}$ of the functional relationship established between WPA and JRC decreased from 0.9643 to 0.9311 . In practice, a small sampling interval is recommended; otherwise, the prediction accuracy will be reduced.

The JRCs of 21 joint profiles in the literature were obtained by the new statistical parameter WPA, and their values were significantly different in two directions. Besides, the point cloud data of four natural rock joint surfaces were obtained by 3D scanning technology. The roughness of each joint surface in 24 shear directions was described by JRC of the obtained 12 joint profiles, and it had been proved to be highly anisotropic. It could be confirmed that the new statistical parameter WPA proposed in this paper could well describe the joint roughness considering the shear direction and the contribution of different protrusions.

\section{Data Availability}

The data used to support the findings of this study are included within the article.

\section{Conflicts of Interest}

The authors declare that they have no conflicts of interest.

\section{Acknowledgments}

This study was funded by the National Natural Science Foundation of China (11902249, 51179153, and 11872301), Natural Science Basic Research Program of Shaanxi (2020JM-453), and Scientific Research Program of Shaanxi Provincial Education Department (17JS091 and 2019JQ395).

\section{References}

[1] D. D. Pollard and P. Segall, "Theoretical displacements and stresses near fractures in rock: with applications to faults, joints, veins, dikes, and solution surfaces," Fracture Mechanics of Rock, vol. 13, no. 8, pp. 277-349, 1987.

[2] X. Yang, P. H. S. W. Kulatilake, H. Jing, and S. Yang, "Numerical simulation of a jointed rock block mechanical behavior adjacent to an underground excavation and comparison with physical model test results," Tunnelling and Underground Space Technology, vol. 50, pp. 129-142, 2015.

[3] M. M. He, Z. Q. Zhang, J. Ren et al., "Deep convolutional neural network for fast determination of the rock strength parameters using drilling data," International Journal of Rock Mechanics and Mining Sciences, vol. 123, 2019.

[4] M. He, Z. Zhang, J. Zheng, F. Chen, and N. Li, "A new perspective on the constant $\mathrm{mi}$ of the hoek-brown failure criterion and a new model for determining the residual strength of rock," Rock Mechanics and Rock Engineering, vol. 53, no. 9, pp. 3953-3967, 2020.

[5] Z. C. Tang, Q. Z. Zhang, and J. Peng, "Effect of thermal treatment on the basic friction angle of rock joint," Rock Mechanics and Rock Engineering, vol. 53, no. 4, pp. 1973-1990, 2020.

[6] E. Hoek, "Strength of jointed rock masses," Géotechnique, vol. 33, no. 33, pp. 187-223, 1983.
[7] F. D. Patton, "Multiple modes of shear failure in rock," in Proceeding of the Congress of International Society of Rock Mechanics, pp. 509-513, Lisbon, Portugal, September 1966.

[8] N. Barton, "Review of a new shear-strength criterion for rock joints," Engineering Geology, vol. 7, no. 4, pp. 287-332, 1973.

[9] N. Barton and V. Choubey, "The shear strength of rock joints in theory and practice," Rock Mechanics, vol. 10, no. 1-2, pp. 1-54, 1977.

[10] N. R. Barton, "Suggested methods for the quantitative description of discontinuities in rock masses," International Journal of Rock Mechanics \& Mining Science \& Geomechanics Abstracts, vol. 15, no. 6, pp. 319-368, 1978.

[11] A. J. Beer, D. Stead, and J. S. Coggan, "Technical note estimation of the joint roughness coefficient (JRC) by visual comparison," Rock Mechanics and Rock Engineering, vol. 35, no. 1, pp. 65-74, 2002.

[12] S. M. Hsiung, A. Ghosh, M. P. Ahola, and A. H. Chowdhury, "Assessment of conventional methodologies for joint roughness coefficient determination," International Journal of Rock Mechanics and Mining Sciences \& Geomechanics Abstracts, vol. 30, no. 7, pp. 825-829, 1993.

[13] N. Barton and S. Bandis, "Effects of block size on the shear behavior of jointed rock," The 23rd U.S Symposium on Rock Mechanics (USRMS) American Rock Mechanics Association, pp. 739-760, 1982.

[14] S. G. Du, Y. Chen, and L. B. Fan, "Mathematical expression of JRC modified straight edge," Journal of Engineering Geology, vol. 4, no. 2, 1996, in Chinese.

[15] N. Turk, M. Greig, W. Dearman, and F. Amin, "Characterization of rock joint surfaces by fractal dimension," in Proceedings of the U.S.Symposium on Rock Mechanics, Tucson, Arizona, June 1987.

[16] Y.-H. Lee, J. R. Carr, D. J. Barr, and C. J. Haas, “The fractal dimension as a measure of the roughness of rock discontinuity profiles," International Journal of Rock Mechanics and Mining Sciences \& Geomechanics Abstracts, vol. 27, no. 6, pp. 453-464, 1990.

[17] R. Tse and D. M. Cruden, "Estimating joint roughness coefficients," International Journal of Rock Mechanics and Mining Sciences \& Geomechanics Abstracts, vol. 16, no. 5, pp. 303-307, 1979.

[18] Z. Y. Yang, S. C. Lo, and C. C. Di, "Reassessing the joint roughness coefficient (JRC) estimation using Z 2," Rock Mechanics and Rock Engineering, vol. 34, no. 3, pp. 243-251, 2001.

[19] X. Yu and B. Vayssade, "Joint profiles and their roughness parameters," International Journal of Rock Mechanics and Mining Sciences \& Geomechanics Abstracts, vol. 28, no. 4, pp. 333-336, 1991.

[20] B. S. A. Tatone and G. Grasselli, "A new 2D discontinuity roughness parameter and its correlation with JRC," International Journal of Rock Mechanics and Mining Sciences, vol. 47, no. 8, pp. 1391-1400, 2010.

[21] H.-S. Jang, S.-S. Kang, and B.-A. Jang, "Determination of joint roughness coefficients using roughness parameters," Rock Mechanics and Rock Engineering, vol. 47, no. 6, pp. 2061-2073, 2014.

[22] B. Zheng and S. Qi, "A new index to describe joint roughness coefficient (JRC) under cyclic shear," Engineering Geology, vol. 212, pp. 72-85, 2016.

[23] N. H. Maerz, J. A. Franklin, and C. P. Bennett, "Joint roughness measurement using shadow profilometry," International Journal of Rock Mechanics and Mining Sciences \& Geomechanics Abstracts, vol. 27, no. 5, pp. 329-343, 1990. 
[24] G. Zhang, M. Karakus, H. Tang, Y. Ge, and L. Zhang, "A new method estimating the 2D Joint Roughness Coefficient for discontinuity surfaces in rock masses," International Journal of Rock Mechanics and Mining Sciences, vol. 72, pp. 191-198, 2014.

[25] T. Belem, F. Homand-Etienne, and M. Souley, "Quantitative parameters for rock joint surface roughness," Rock Mechanics and Rock Engineering, vol. 33, no. 4, pp. 217-242, 2000.

[26] P. H. S. W. Kulatilake, G. Shou, T. H. Huang, and R. M. Morgan, "New peak shear strength criteria for anisotropic rock joints," International Journal of Rock Mechanics and Mining Sciences \& Geomechanics Abstracts, vol. 32, no. 7, pp. 673-697, 1995.

[27] F. Homand, T. Belem, and M. Souley, "Friction and degradation of rock joint surfaces under shear loads," International Journal for Numerical and Analytical Methods in Geomechanics, vol. 25, no. 10, pp. 973-999, 2001.

[28] B. Liu, H. B. Li, and X. M. Zhu, "Experiment simulation study of strength degradation of rock joints under cyclic shear loading," Chinese Journal of Rock Mechanics \& Engineering, vol. 30, no. 10, pp. 2033-2039, 2011, in Chinese.

[29] B. Liu, H. B. Li, and Y. Q. Liu, "Experimental study of deformation behavior of rock joints under cyclic shear loading," Rock and Soil Mechanics, vol. 34, no. 9, pp. 2475-2481, 2013, in Chinese.

[30] B. Li, Y. Jiang, T. Mizokami, K. Ikusada, and Y. Mitani, "Anisotropic shear behavior of closely jointed rock masses," International Journal of Rock Mechanics and Mining Sciences, vol. 71, pp. 258-271, 2014.

[31] Z.-c. Tang, Q.-s. Liu, and J.-h. Huang, "New criterion for rock joints based on three-dimensional roughness parameters," Journal of Central South University, vol. 21, no. 12, pp. 4653-4659, 2014.

[32] Z.-C. Tang, Q.-S. Liu, C.-C. Xia, Y.-L. Song, J.-H. Huang, and C.-B. Wang, "Mechanical model for predicting closure behavior of rock joints under normal stress," Rock Mechanics and Rock Engineering, vol. 47, no. 6, pp. 2287-2298, 2014.

[33] J.-W. Park and J.-J. Song, "Numerical simulation of a direct shear test on a rock joint using a bonded-particle model," International Journal of Rock Mechanics and Mining Sciences, vol. 46, no. 8, pp. 1315-1328, 2009.

[34] J.-W. Park and J.-J. Song, "Numerical method for the determination of contact areas of a rock joint under normal and shear loads," International Journal of Rock Mechanics and Mining Sciences, vol. 58, pp. 8-22, 2013.

[35] R. Kumar and A. K. Verma, "Anisotropic shear behavior of rock joint replicas," International Journal of Rock Mechanics and Mining Sciences, vol. 90, pp. 62-73, 2016.

[36] Y. C. Li, W. Wu, and B. Li, “An analytical model for two-order asperity degradation of rock joints under constant normal stiffness conditions," Rock Mechanics and Rock Engineering, vol. 1, pp. 1-15, 2018.

[37] Y. C. Li, Z. Z. Liang, C. A. Tang, D. Q. Li, and C. Z. Wu, "Analytical modelling of the shear behaviour of rock joints with progressive degradation of two-order roughness," International Journal for Numerical and Analytical Methods in Geomechanics, vol. 43, no. 3, 2019.

[38] N. E. Odling, "Natural fracture profiles, fractal dimension and joint roughness coefficients," Rock Mechanics and Rock Engineering, vol. 27, no. 3, pp. 135-153, 1994.

[39] A. Özvan, İ. Dinçer, A. Acar, and B. Özvan, "The effects of discontinuity surface roughness on the shear strength of weathered granite joints," Bulletin of Engineering Geology and the Environment, vol. 73, no. 3, pp. 801-813, 2014.
[40] R. Yong, J. Ye, Q. F. Liang, M. Huang, and S. G. Du, "Estimation of the joint roughness coefficient (JRC) of rock joints by vector similarity measures," Bulletin of Engineering Geology \& the Environment, vol. 77, no. 2, pp. 1-15, 2017.

[41] J. Ye, R. Yong, Q.-F. Liang, M. Huang, and S.-G. Du, "Neutrosophic functions of the joint roughness coefficient and the shear strength: a case study from the pyroclastic rock mass in shaoxing city, China," Mathematical Problems in Engineering, vol. 2016, pp. 1-9, 2016. 